\title{
Christelle Reggiani, Éloquence du roman. Rhétorique, littérature et politique aux $\mathrm{XIX}^{\mathrm{e}}$ et $\mathrm{XX}^{\mathrm{e}}$ siècles
}

\section{Tobia Zanon}

\section{OpenEdition}

\section{Journals}

\section{Edizione digitale}

URL: http://journals.openedition.org/studifrancesi/7686

DOI: $10.4000 /$ studifrancesi.7686

ISSN: 2427-5856

\section{Editore}

Rosenberg \& Sellier

\section{Edizione cartacea}

Data di pubblicazione: 1 décembre 2009

Paginazione: 662

ISSN: 0039-2944

\section{Notizia bibliografica digitale}

Tobia Zanon, "Christelle Reggiani, Éloquence du roman. Rhétorique, littérature et politique aux xix et $x x^{\mathrm{e}}$ siècles», Studi Francesi [Online], 159 (LIII | III) | 2009, online dal 30 novembre 2015, consultato il 09 janvier 2021. URL: http://journals.openedition.org/studifrancesi/7686 ; DOI: https://doi.org/10.4000/ studifrancesi.7686

Questo documento è stato generato automaticamente il 9 janvier 2021.

\section{(c)}

Studi Francesi è distribuita con Licenza Creative Commons Attribuzione - Non commerciale - Non opere derivate 4.0 Internazionale. 


\title{
Christelle Reggiani, Éloquence du roman. Rhétorique, littérature et politique aux XIX et $X^{\mathrm{e}}$ siècles
}

\author{
Tobia Zanon
}

\section{NOTIZIA}

CHRISTELLE REGGIANI, Éloquence du roman. Rhétorique, littérature et politique aux XIXe et XX siècles, Genève, Droz, 2008 («Histoire des idées et critique littéraire», 439), pp. 230.

1 A partire dalla seconda metà del XIX secolo si assiste in Francia a una "rivoluzione": il tradizionale giudizio negativo dato, nel suo complesso, all'apparato della Retorica dal Romanticismo, viene rovesciato, e quest'ultima - intesa soprattutto come analisi dei fenomeni enunciativi e argomentativi - diviene "istituzionalmente" (nel senso che trova un suo posto nelle sedi istituzionali della cultura e dell'insegnamento come, per esempio, le prove del baccalauréat o i corsi universitari) uno degli approcci metodologicamente centrali e privilegiati per la lettura dei testi letterari. A partire da queste premesse, Reggiani si lancia nel coraggioso tentativo di tracciare una «histoire rhétorique de la littérature des $\mathrm{XIX}^{\mathrm{e}}$ et $\mathrm{XX}^{\mathrm{e}}$ siècles» (p.10), che indaghi in qualche modo $\mathrm{i}$ risultati "creativi" di questa recuperata centralità della Retorica. Non solo, dunque, in fase di lettura, ma anche di stesura di un testo letterario. L'A. si muove quindi accortamente consapevole della stringente e ineluttabile necessità di organizzare la propria ricerca attorno ad alcuni - pochi, ma estremamente funzionali - assi di lettura, che sono: (1) la scelta del "fatto retorico" (inteso nel senso disciplinarmente più ampio) come lente attraverso cui leggere i testi di un (2) corpus costituito esclusivamente da prose narrative risalenti (3) a un determinato periodo cronologico: l'Otto e il Novecento. L'epoca della "rinascita" della Retorica, come vede bene Reggiani, coincide in buona sostanza con la grande epoca della scrittura romanzesca francese. 
2 Dal punto di vista della sua struttura interna, il volume si apre su due capitoli di taglio storico-metodologico: il primo ripercorre il ritorno in auge della Retorica a partire dal suo rientro nelle materie d'insegnamento scolastico, mentre il secondo analizza l'impatto sul Novecento di tre testi centrali della "memoria" retorica: Letteratura europea e Medio Evo latino di Curtius, il Trattato dell'argomentazione. La nuova retorica di Perelman e Olbrechts-Tyteca, e La retorica antica di Barthes. È infatti attorno a questi tre fondamentali testi, autentiche opere-cardine che si costruiscono le coscienze e conoscenze retoriche nella seconda metà del secolo. Dopo questa indispensabile messa a punto, vengono finalmente affrontati i testi: i capitoli 3 e 4 si soffermano sul periodo che va dalla metà del xIx ai primi anni del xx secolo, mentre i capitoli 5 e 6 fanno i conti non solo con i grandi nomi (e le grandi prose) del pieno Novecento francese - due emergenze su tutte: Proust e Céline -, ma fanno anche molto opportunamente reagire tutti i fenomeni diversamente riconducibili al "fatto retorico" (inteso non solo come manifestazione generale, ma anche come insieme delle singole concezioni della Retorica individuabili nelle poetiche dei diversi autori) con il suo ruolo in una Società dall'orizzonte politico e culturale cangiante e frastagliato com'è quello del Novecento europeo. 